\title{
The Nature and Limits of the Duty of Rescue
}

\begin{abstract}
Virtually everyone believes that we have a duty to rescue fellow human-beings from serious danger when we can do so at small cost to ourselves - and this often forms the starting point for arguments in moral and political philosophy on topics such as global poverty, state legitimacy, refugees, and the donation of body parts. But how are we to explain this duty, and within what limits does it apply? It cannot be subsumed under a wider consequentialist requirement to prevent harm. Nor can it be understood as a duty of social justice that citizens owe to one another under a social contract for mutual protection. Instead it is a sui generis duty of justice that arises from the direct physical encounter between rescuer and victim, and is accordingly limited in scope. However the simplicity of the duty evaporates when multiple potential rescuers are present. Here responsibility lies with the collective as a whole until it is assigned by a fair procedure to individual members. Each individual is required as a matter of justice to discharge that share, but not more, though in the case that others do not comply, he will have a reason, and sometimes a humanitarian duty, to take up the slack.
\end{abstract}

Keywords: Duties, Proximity, Rescue, Responsibility, Rights ।

Virtually everybody believes that there is such a thing as the duty of rescue. When one encounters a fellow human being whom one can save from death or serious harm at relatively small cost to oneself, one has a duty to do so. The classic example, introduced by Peter Singer and much-discussed since, involves a passer-by pulling a drowning child out of a shallow pond at the cost of getting his clothes muddy. ${ }^{1}$ Confronted with the example, almost everyone agrees that the passer-by has a duty to save the child, that it would be seriously wrong for him to carry on walking just because he is going to miss an appointment or doesn't want to spoil his suit. ${ }^{2}$

That seems to be one of our most firmly-held our moral intuitions. But it does not follow that the duty of rescue is well understood. To what extent does our reaction to Singer's example depend on its having specific features that may not be present in other cases where a rescue might be called for $?^{3}$ Consider just some of these. The child is only a child,

\footnotetext{
${ }^{1}$ Peter Singer, 'Famine, Affluence and Morality,' Philosophy and Public Affairs 1 (1972), pp. 229-43.

2 'Almost everyone' because some philosophers may argue that what is at issue here is something less than a duty. They will say that it is morally reprehensible for the passer-by to ignore the child, but there is no obligation to go to the rescue; the child does not have a right to be rescued. See, for example, Judith Thomson, 'A Defence of Abortion,' Philosophy and Public Affairs 1 (1971), pp. 47-66.
} 
and therefore not responsible for having got herself into difficulties. The rescue will have no further consequences beyond the saved child and the ruined suit: there are no other children around, so no danger that any of them will be tempted to jump into the pond in anticipation of being rescued. And the child herself, we would naturally assume, will be returned to her anxious parents and live a happy life thereafter - so the cost of the rescue is very small compared to the expected benefit. If we were to change some of these features, for instance by introducing multiple possible rescuers, or by turning the child into a young adult who has ignored a large warning sign advising him not to swim, then we might begin to wonder whether the man in the expensive suit still has a duty, as opposed merely to a reason, to plunge into the pond.

My aim in this article is to explore both the character and the scope of the duty of rescue. I begin with the simplest case where only a single rescuer is present at the scene before turning in section IV to multi-rescuer cases. I argue that the duty of rescue is a duty of justice: the victim has a right to be rescued, and correlative to that the potential savior has an enforceable moral obligation to carry out the rescue. But the duty is triggered by special features of the relationship between victim and rescuer, which entails that in normal cases the two must be physically proximate. To prove that the duty is sui generis in this sense, I begin by showing that neither consequentialists nor contractualists have been able to explain it satisfactorily.

When multiple rescuers are present, I claim that the duty of rescue initially falls on the rescuers collectively who must then distribute it fairly among themselves. Once responsibilities have been assigned, each individual rescuer has a duty of justice to play their allotted part in the rescue. If some fail to do this, however, those who have already complied may have a further humanitarian duty to take up the slack. I go on to point out some relevant differences between this secondary duty of rescue and the primary one.

At various points in the article I appeal to intuitions about what a person is or is not obliged to do when confronted with a situation in which a rescue is required. Readers may not initially share all of these intuitions, so I also try to suggest justifications for some of them for example the intuition that it matters that the rescuer is physically close to the person in 
need of rescue. I hope in this way to develop a plausible account of the shape of the duty of rescue. But I recognize that this may not convince those who are already firmly committed to one of the overarching moral theories discussed in section II. For people in this category, the article should present a challenge: is it indeed possible to accommodate a specific duty of rescue within a general moral theory of consequentialist or contractualist stripe?

Since in the real world, unlike in books of philosophy, rescue cases involving civilians are happily quite rare, why is it important to clarify the nature and limits of the duty of rescue? One good reason is that this duty is often used as a touchstone when discussing more general issues in moral and political philosophy. In Singer's own case, it is used to justify the claim that citizens of rich societies are morally obliged to contribute a significant part of their income to relieving famine and poverty globally. ${ }^{4}$ For others it explains why liberal democracies have a duty to aid refugees fleeing from persecution or violence. ${ }^{5}$ It has been invoked to prepare the ground for an argument that the able-bodied are under an obligation to supply body parts, such as blood and bone marrow, to those who cannot live a minimally decent life without them. ${ }^{6}$ It has also been used to ground the so-called 'Samaritan' theory of political legitimacy and political obligation, whose central claim is that the duties we have to protect others from the perils of the state of nature can justify the state's imposing on us obligations of law observance and so forth. ${ }^{7}$ In each case the duty of rescue is appealed to as proof that we have positive duties to save others from serious harm, and this result is then transposed to other circumstances in which harm is threatened without involving rescue in the most literal sense of the term. So if we are going to judge

As Singer puts it, 'we have an obligation to help those in absolute poverty that is no less strong than our obligation to rescue a drowning child from a pond' (Peter Singer, Practical Ethics (Cambridge: Cambridge University Press, 1993), p. 230).

${ }^{5}$ See, for example Alexander Betts and Paul Collier, Refuge: Transforming a Broken Refugee System (London: Allen Lane, 2017), ch. 4.

${ }^{6}$ See Cecile Fabre, Whose Body is it Anyway? Justice and the Integrity of the Person (Oxford: Clarendon Press, 2006), chs. 2-5.

7 See Christopher Wellman, 'Toward a Liberal Theory of Political Obligation,' Ethics 111 (2001), pp. 735-59, reprinted in Christopher Wellman, Liberal Rights and Responsibilities (New York: Oxford University Press, 2014), pp. 53-74. 
whether these various moral and political arguments by analogy are sound, we need to start with a clear understanding of the duty of rescue itself.

In one article, I cannot hope to answer all of the questions that might be asked about the duty, so let me quickly signal three issues that will be left aside. The first is whether duties of rescue should be made legally enforceable. Some states currently have so-called Bad Samaritan laws on their books, while others do not, and I think there can be reasonable disagreement over which side has the better arguments here. ${ }^{8}$ Although as I have indicated I take the duty of rescue to be an enforceable duty of justice, legal enforcement raises special questions about the legitimate purposes of law that are beyond my scope. Second, I shall not try to establish what the upper limit is to the cost that a rescuer can be required to bear in the course of rescuing a victim from death or serious harm. It is generally understood that the cost must be significantly less than the harm that would accrue to the victim if the rescue were not performed, but it is difficult to be more precise than that. ${ }^{9}$ Third, I shall not ask what difference it makes to the duty if the victim is wholly or partly responsible for getting into the predicament from which he needs to be saved. Do people who fall into this category have a weaker claim to be rescued, and does it make a difference to the risks and harms that the rescuer can be asked to bear? These difficult questions deserve their own paper. Setting them aside here, the next section asks whether the duty of rescue can be understood either in consequentialist or in contractualist terms.

II

For consequentialists such as Singer, our firm intuition about the pond case suggests that we are committed to the much wider principle that 'if it is in our power to prevent something bad from happening, without thereby sacrificing anything of comparable moral importance, we ought, morally, to do it. ${ }^{10}$ Here, then, the duty of rescue is subsumed under the general

${ }^{8}$ To sample the debate, see James Ratcliffe (ed.), The Good Samaritan and the Law (Garden City: Anchor Books, 1966); Ernest Weinrib, 'The Case for a Duty to Rescue,' Yale Law Journal 90 (1980-1), pp. 247-93; Joel Feinberg, 'The Moral and Legal Responsibility of the Bad Samaritan,' Criminal Justice Ethics 3 (1984), pp. 56-69; Alison McIntyre, 'Guilty Bystanders? On the Legitimacy of Duty to Rescue Statutes,' Philosophy and Public Affairs 23 (1994), pp. 157-91; Arthur Ripstein, 'Three Duties to Rescue: Moral, Civil, and Criminal,' Law and Philosophy 19 (2000), pp. 751-79; Heid Malm, 'Bad Samaritan Laws: Harm, Help or Hype?,' Law and Philosophy 19 (2000), pp. 707-50. 9

For an acute discussion of how the costs of rescue condition the duty, see Fiona Woollard, Doing and Allowing Harm (Oxford: Oxford University Press, 2015), ch. 7. 10 
duty to prevent harm when we can do so without incurring unreasonable costs. But once we begin to vary the original example, this subsuming move looks more questionable. Notice that rescuing a drowning victim may also be an instance of causing or failing to prevent harm. Consider, for example, a case in which the would-be rescuer is engaged in a task that if brought to fruition would save a number of lives as opposed to the single life of the rescuee - let's say he is hurrying to catch the weekly plane that will convey him to direct a famine relief operation in Africa; without his presence, the operation will stall. If we think that the passer-by is nonetheless under a duty to rescue the drowning child even if this will cause him to miss the plane, then the duty cannot be understood in straightforwardly consequentialist terms. Or consider a case where the person who needs to be rescued is an evil-doer who will continue to harm others if he is saved from death. Most would say that that we should nevertheless pull Pol Pot, or whoever it is, out of the quicksand. ${ }^{11}$

Faced with these examples, a consequentialist might respond in either of two familiar ways. One is to bite the bullet and deny that there is such a thing as a specific duty of rescue; instead there is only a general duty to minimize the incidence of harm, so the Oxfam professional should pass by the child and catch his plane, and Pol Pot should be left to his fate. The widely held belief that it is morally obligatory to rescue a person who is directly encountered and clearly endangered, without regard to wider consequences, is to be explained away in psychological terms. ${ }^{12}$ The other is to present the duty of rescue as a practical rule that should be followed unless there is compelling evidence that more harm can be averted by breaching it. Usually, there are good consequentialist reasons for saving the person immediately in front of you: the greater certainty of the immediate rescue,

\footnotetext{
Singer, 'Famine, Affluence and Morality,' p. 231.

${ }^{11}$ Not everyone agrees with this, however. We need to distinguish between the case in which the person sinking in the quicksand poses an immediate threat to those around him, and the case in which the harm that he will perpetrate lies further in the future. In the former case, leaving him to sink can be justified as an act of self- or other-defense, whereas in the latter case it cannot. My claim, then, is that we have a duty to rescue the evil-doer unless leaving him to die can be assimilated to a case of killing in self-defense.
} 12

See, for example, Unger's sustained attempt to explain the differences between our reactions to rescue situations and our reactions to appeals for aid on behalf of starving people in far-off continents in terms of the greater conspicuousness of persons' needs in the former case, a factor that he treats as psychologically powerful but morally irrelevant, in Peter Unger, Living High and Letting Die: Our Illusion of Innocence (New York: Oxford University Press, 1996). 
versus the probabilistic calculations of long-term consequences you would need to make to justify passing by. You cannot know for certain that another Oxfam professional will not turn up out of the blue to direct the famine relief operation, or that the experience of being rescued won't change the evil dictator into a Mother Teresa.

Neither of these consequentialist responses seems satisfactory to me. Neither adequately captures the compelling nature of the duty of rescue: our belief that we have a strict obligation to save the immediate victim, corresponding to a right on her part to be rescued from harm. This belief persists even if it is absolutely certain that the would-be rescuer could avert more harm or prevent more deaths by ignoring the victim and continuing on his way. Of course the source of this belief must be explained in a way that does not undermine it. We need to understand how a direct encounter between two previously unrelated people can generate a directed obligation towards the victim. This obligation, moreover, is an enforceable duty of justice. A third party who is present at the scene but unable to carry out the rescue herself can use reasonable force to spur the reluctant Samaritan into action. So if I cannot swim myself, but I share the beach with a strong swimmer who is complacently looking on as a drowning bather struggles, I can threaten to throw the swimmer's expensive camera into the sea if he doesn't go to the rescue. ${ }^{13}$

A consequentialist approach cannot explain why the duty of rescue should be a duty of justice as described above. But we still need to know how a positive duty of this kind positive in the sense that it requires the rescuer to take action to avert impending harm, and not merely to refrain from causing harm - could arise. ${ }^{14}$ Philosophers of libertarian or Kantian stripe will think that all general duties of justice are negative in character: broadly speaking, they are duties of non-interference. Positive duties are created only by specific

13

I shall not try to specify what counts as 'reasonable force' in such a case. Nor shall I broach the question of whether it is permissible to carry out the threat one has made in case it is not complied with. It appears to me, however, that if the initial threat does not succeed, it will be justifiable to carry out some part of it - unscrew the expensive camera's lens and toss it into the water, for example - to convince the unwilling rescuer that the original threat was serious.

${ }^{14}$ I assume here that the duty to rescue is indeed a positive duty. A number of legal philosophers have attempted to explain it by reference to the negative duty to avoid causing harm to others (see especially Joel Feinberg, The Moral Limits of the Criminal Law, Volume 1: Harm to Others (New York: Oxford University Press, 1984), ch. 4). For a thoroughgoing critique of this position, see McIntyre, 'Guilty Bystanders?.' 
transactions, such as making a contract or taking on a role (for instance becoming a lifeguard or a paramedic). From this perspective, it is hard to fathom how the duty of rescue, understood as a duty owed by one individual to another on the basis of a chance encounter, could be a duty of justice.

Faced with this difficulty, several authors have proposed that the duty of rescue forms part of the implicit social contract that citizens have entered into as members of the political community. ${ }^{15}$ The general picture they present is this: we enter the state and submit to its requirements in order to protect our basic rights. Most of the time we contribute to this end indirectly, through obeying the law, paying our taxes, and so forth. There are, though, occasions when our role as citizens requires us to take direct action. If we see a fire breaking out, we should report it to the fire service. If we witness criminal behavior, we should again alert the authorities, or in some cases even intervene to prevent the crime if we can do so safely. On these occasions we are temporarily conscripted, so to speak, to act on behalf of the political community, since this is necessary to protect the rights of our fellow citizens. The duty of rescue forms part of this implicit contract.

This proposal may seem attractive, because seen in this light the duty of rescue, as a positive duty of justice, no longer looks like an outlier. It becomes just one element in the broader duty we have as citizens to help achieve social justice. But I am doubtful that the duty can really be explained in this way. ${ }^{16}$ Instead it is a duty that one human being owes to another regardless of any pre-existing social or political relationship that may obtain between them. Thus (all else equal) I have just as compelling an obligation to rescue a stranger when traveling in a foreign land as I do to rescue a person in my home country whom I can expect to be a fellow citizen. There are certainly many things I ought to do for a fellow citizen that I need not do for the stranger, but rescuing a person from immediate peril does not belong on that list.

15

See, for example Steven Heyman, 'Foundations of the Duty to Rescue,' Vanderbilt Law Review 47 (1994), pp. 673-755; McIntyre, 'Guilty Bystanders?'; Ripstein, 'Three Duties to Rescue'; Laura Valentini, 'Social Samaritan Justice: When and Why Needy Fellow Citizens Have a Right to Assistance,' American Political Science Review 109 (2015), pp. 735-49. 16

For a fuller critique of the citizenship approach, see Cecile Fabre, 'Good Samaritanism: A Matter of Justice,' Critical Review of International Social and Political Philosophy 10 (2002), pp. 130-132. 
But, someone might ask, what if you have to choose between rescuing someone you know to be a co-national and someone you know to be a foreigner, assuming that they are equally at risk of harm? Many, though not everyone, would say that in those circumstances you should save your compatriot in preference to the foreigner. I share that view, but it doesn't follow that the duty of rescue itself is grounded in the special relationship that exists between fellow citizens. Here I need to say something about the general case in which a rescuer is faced with a choice between saving two people, when he cannot save both. Under these circumstances, he can discharge his duty of rescue by saving either of the two victims. The unlucky victim does not have a right against that rescuer to be saved, because the rescuer's obligation to that person is forestalled by virtue of the fact that he is discharging his obligation to the person he has chosen, making it impossible for him to perform the obligation he would otherwise have had to save the second person. Whichever choice he makes, neither victim can claim to have been wronged. ${ }^{17}$ However, the rescuer may still have reasons to prefer saving one of the two. For example, she may be a friend or a family member. Or there may be consequential reasons that tell in favor of saving $A$ rather than B. My view is that compatriot partiality can also count as such a reason. So faced with a choice between saving a fellow national and saving a foreigner, the balance of reasons will usually tell me to rescue my compatriot, but it would not be a breach of the duty of rescue itself if I chose to save the foreigner. The compatriot could not complain that her rights had been violated, though she might fault me for not showing enough solidarity.

That the duty of rescue itself is impartial in this way can be confirmed by considering the costs that it would be reasonable to ask the rescuer to bear to protect the victim from a specified degree of harm, ultimately from death itself. If she owed a stronger duty of rescue to her compatriots, then one would expect that the cost threshold would be higher in their 17

A point made forcefully in G. E. Anscombe, 'Who is Wronged?,' Oxford Review 5 (1967), pp. 16-17. As Anscombe concedes, however, if the potential rescuer does nothing, he wrongs both victims. So we should say that both people have a right to be rescued, but that this translates into an obligation on the part of the rescuer only if he is able to carry out the rescue. By undertaking to rescue $A$, he permissibly becomes unable to rescue $B$ (in contrast, say, to handcuffing himself to a nearby tree to avoid the cost of rescuing $B$, which would be impermissible).

Anscombe also notes that there can be bad reasons for choosing A over B. If I prefer to save the white victim on grounds of race, I do not violate the black victim's right to be saved, but I do disrespect her, and if there is a right against discrimination, as many believe, I violate that right. 
case. But my intuition is that the cost threshold does not shift between compatriots and foreigners. Here I mean the costs inherent in the rescue itself, especially the risks to which the rescuer exposes herself. She may owe a compatriot more by way of follow-up assistance, emulating the Good Samaritan who not only bandaged the wounds of the man who had fallen among thieves but took him to a nearby inn and paid the innkeeper's bill in advance - the point of the parable being to show what it meant to be a good neighbor to someone. The Samaritan did much more than the duty of rescue alone required.

I have rejected a contractarian explanation of the duty of rescue that understands it as part of a wider duty that citizens owe to one another to help promote social justice. One might turn instead to an alternative form of contractarianism that does not tie moral obligation in that way to membership of a political community. Scanlon, for example, defends what he calls the Rescue Principle, according to which 'if you are presented with a situation in which you can prevent something very bad from happening, or alleviate someone's dire plight, by making only a slight (or even moderate) sacrifice, then it would be wrong not to do so.' ${ }^{18}$ However this principle (which, as he notes, is in substance not so different from Singer's harm-prevention principle) fails to explain what is significant about rescue in the literal sense - what sets the case where one directly confronts a person in imminent danger of death or serious injury apart from the wider set of circumstances in which we have opportunities to prevent harm or alleviate deprivation. So if we remain convinced that the duty of rescue is special in that way, it seems that neither consequentialist nor contractarian moral theories have the resources to explain why.

III

To make good on this claim about the distinctiveness of the duty of rescue, we need to explain how the direct confrontation between victim and potential rescuer can impose an obligation on the latter. The problem is not to explain why the victim's predicament gives rise to a duty - that is accounted for by the severe harm to which the victim is exposed, together with the fact that the rescue can be carried out at small cost to the rescuer. The problem is explaining why the rescuer should be singled out as a duty-bearer merely by

${ }^{18}$ T. M. Scanlon, What We Owe to Each Other (Cambridge, MA: Harvard University Press, 1998), p. 224. 
virtue of her temporary proximity to the victim. ${ }^{19}$ How does the latter acquire a right against someone who merely happens to be passing the place in question, or sitting on the beach, imposing on them a positive duty to act? Or as one legal opinion puts it, how can 'mere accidental propinquity' give rise to an enforceable positive duty when there has been no previous relationship between the parties? ${ }^{20}$ Many find it indefensible that distance should count in this way - indeed that was precisely Singer's point when he argued that we have as strong a reason to save a famine victim thousands of miles away as to rescue the child drowning in the pond. Even if we have the intuition, contrary to Singer, that physical closeness matters, we need to be able to say more to justify it. Given that the victim's need of help, and the rescuer's capacity to supply it, will always give the rescuer some reason to act, we need to explain why being close to the victim can turn that reason into an enforceable duty for the rescuer. ${ }^{21}$

Since physical distance has no intrinsic moral significance, what we need to show is that being close to each other creates some feature of the relationship between rescuer and victim that is morally relevant, so that taken together with the general justification referred to above, a duty of rescue will arise. ${ }^{22}$ The simplest account would involve finding a single 19

It can of course be argued that it is some other factor having nothing essentially to do with proximity that explains why the duty of rescue takes the form that it does: see for example Violetta Igneski, 'Distance, Determinacy and the Duty to Aid: A Reply to Kamm,' Law and Philosophy 20 (2001), pp. 605-16.

20

Lord Reid, in The Home Office $v$. The Dorset Yacht Company Ltd., available at http://www.bailii.org/uk/cases/UKHL/1970/2.html. Reid concedes, however, that although there cannot be a legal duty in such a case, there might be 'a moral duty.'

${ }^{21}$ I won't attempt here to give a full account of how moral duties differ from other moral reasons. I assume that they are more stringent - normally a duty can be defeated only by another duty - and that they expose the duty-bearer to sanctions of various kinds - blame, punishment, etc. - if not performed. Nor shall I try to answer the question 'when do moral reasons become duties?.' It seems to me doubtful that any general answer can be given to that question, when we consider the diversity of duties, as cataloged say by W.D. Ross in The Right and the Good (Oxford: Clarendon Press, 1930), and the circumstances that give rise to them. 22

Frances Kamm has examined in some detail what she calls 'The Problem of Distance in Morality,' and although I have benefited considerably from reading Kamm's work, I should make it clear that I am not attempting to follow her in asking whether in general we have more reason to attend to the physically proximate effects of our actions than to the more distant effects. My focus is on the narrower question of the role played by proximity in explaining the shape of the duty of rescue as a duty of justice. See Kamm, 'Does Distance Matter Morally to the Duty to Rescue?'; Frances Kamm, Intricate Ethics: Rights, Responsibilities, and Permissible Harm (New York: Oxford University Press, 
feature that was always tightly tied to proximity. But if no such feature can be found, there is a second possibility. There might be several features that normally accompany proximity, such that in standard cases all of them would be present when rescuer and victim are close, but one or more might occasionally occur in other cases too. This would open the way for a mildly revisionist account of the duty of rescue, such that the duty applies whenever the potential rescuer and her victim are close to each other, but might also apply in special cases when they are further apart. On that revisionist view, therefore, proximity would still be important to explaining the duty of rescue, by virtue of being a sufficient condition for the duty to obtain, but not in every instance a necessary one.

With these possibilities in mind, let me examine some factors that might plausibly explain the relevance of proximity. The first is that physical closeness will make the victim uniquely vulnerable to the rescuer's decision whether or not to carry out the rescue. ${ }^{23}$ For the rescue to be carried out successfully, the rescuer has to become aware of the victim's plight, and then be able to act with sufficient speed to save the victim from harm, and both conditions will normally require that the rescuer be close to the victim. Under these circumstances only the rescuer can save the victim from harm. Such unique vulnerability is a feature that distinguishes rescue cases from other instances of aid-giving (such as poverty relief), and so can help to explain why a duty arises here but not in the other cases, and why the victim has a right against the rescuer that would be violated if the rescue is not carried out.

It is of course possible to invent cases in which there is unique vulnerability without proximity as normally understood. For instance, a drone operator might through a remote camera spot someone in peril who could be saved by directing the drone in the appropriate way, and if his was the only drone in the area, the uniqueness condition would be met. If we think that the duty of rescue holds in such a case, then we must either revise our understanding of what it means to be close to the victim, ${ }^{24}$ or, as suggested above, relax the 2007), chs 11-12.

23

Keep in mind that in this part of the article, discussion is restricted to single-rescuer cases, with multiple-rescuer cases postponed to section IV.

${ }^{24}$ Frances Kamm has invented, and discussed in some detail, hypothetical cases in which, although the agent is not in the normal sense physically close to the victim, she controls means of rescue that are close, and therefore proposes that we need to revise our understanding of (morally relevant) distance to accommodate that possibility. For example, she imagines people with long arms that can stretch from one side of India to the other: see Kamm, Intricate Ethics, ch. 11, sect. III. I am inclined 
link between the duty and proximity. Perhaps if such cases became common we would indeed construe the duty more widely. Yet pending such technical developments, at least for individual agents, closeness serves as a good indicator of special vulnerability.

A second factor that normally depends on physical closeness is the generation of a personal encounter between rescuer and victim: the rescuer recognizes the victim as a person in need of help, and the victim likewise understands the rescuer as having the capacity to give it; often the two people will exchange words or looks. A (temporary) relationship is formed, and once the rescuer has directly confronted the victim as another human being in desperate straits, it would be appalling simply to turn and walk away on the grounds that it was inconvenient to offer help. ${ }^{25}$ Now it is of course true that proximity alone does not entail that an encounter must occur: the victim may be lying unconscious as the rescuer approaches, for example. And equally it is possible to contemplate cases of remote encounter, such as through the Internet, though one might question whether such interactions are morally significant in the same way that face-to-face meetings are. But even if proximity is neither necessary nor sufficient for a personal encounter, the fact that in normal circumstances one implies the other may help to explain why physical closeness plays the role that it does in our understanding of the duty of rescue.

A third possible explanation involves the idea of personal space - the area around our bodies over which we claim a kind of moral sovereignty. It doesn't have a precise outer edge, but we nonetheless claim moral rights over a physical domain that others should not intrude upon without our consent. This expresses itself concretely in various ways. It forms one of the bases for personal private property - we want to be able to arrange objects around us according to our needs and our tastes. It also explains what's objectionable about somebody who insists on standing closer to us than we are comfortable with. But if we claim this kind of sovereignty over our personal space, we should also accept some

to think that if this kind of action at a distance were possible, it would revolutionize our understanding of moral agency in a number of ways, and Kamm's scenario is therefore an unreliable guide to the moral landscape that we actually inhabit. 25

For explanations of the significance of proximity that emphasize personal encounter, see Jeremy Waldron, 'Who is My Neighbor?: Humanity and Proximity,' The Monist 86 (2003), pp. 333-54; Soren Reader, 'Distance, Relationship and Moral Obligation,' The Monist 86 (2003), pp. 367-81. In contrast, Woollard treats physical proximity and personal encounter as independent grounds for the duty of rescue in Doing and Allowing Harm, ch. 7. 
responsibility to others for what goes on within it. We should not leave it strewn with hazards for people who might enter it innocently, for example. A natural extension of this thought is that we should take positive responsibility for any harm to others that occurs within that area. So when I find myself close to the person in need of rescue, he falls within my personal domain, and my responsibility in this case takes the form of a duty of rescue that I do not owe to people who are further away. ${ }^{26}$

To this it may be objected that the duty of rescue extends further out than the space over which we claim personal sovereignty. Where I am the only possible rescuer, I may have a duty to save someone from drowning at a distance of fifty or a hundred yards once I become aware of her plight, whereas personal space, as we normally understand it, extends only a few paces beyond a person's own body. But although this may be true in general, there are circumstances in which we feel entitled to claim some degree of control over a wider domain. Consider the case of someone being stalked, where the stalker neither threatens any injury, nor comes very close to his target. ${ }^{27}$ Nevertheless, when the latter looks around, she can often see the stalker lurking there. The person who is being stalked can legitimately demand that the stalking should stop, which means that the stalker must remove himself from the much wider area within which he is visible to his prey. Of course she cannot claim control over everything that happens within that larger domain. But the example shows that the domain of personal space over which we have rights and duties will vary according to what is happening within it. The urgency of a rescue situation may stretch it in one way, while the distressing experience of being stalked stretches it in another.

It might also be objected that if the duty to rescue arises from the special responsibility we owe to others who come within our personal space, then we could escape that duty by

\footnotetext{
${ }^{26}$ Frances Kamm has suggested a somewhat different way of explaining this responsibility, which appeals to the idea that we have a personal prerogative that allows us to give greater weight to our own interests and projects than would be allowable from an impartial perspective: see Kamm, Intricate Ethics, ch. 12, sect. VI. Although I accept such a personal prerogative, I am not convinced that it yields a satisfactory explanation of why we should have greater moral concern for what happens close to us in space.

${ }^{27}$ Stalking appears to be a complex phenomenon, usually involving repeated communication with the target, damage to her property and/or threats of violence. But continued unwanted presence near to the victim is certainly one part of it, and it requires no great imagination to see why this is psychologically damaging and objectionable even if none of the other elements occur.
} 
moving sufficiently far away, where we can no longer see or hear the distressed victim. But this misunderstands how the duty operates: once created through proximity, it remains in full force until it has been discharged, or circumstances have materially changed (for example, because a more competent rescuer has arrived on the scene). What is true, however, is that I have no prior duty to put myself in a position where I am likely to have to carry out a rescue. Someone who deliberately goes out of his way to avoid situations where he might be called upon to engage in a rescue reveals himself to be something of a moral louse, but he does not breach any duty to the victims he might otherwise have saved. ${ }^{28}$ If successful, the personal space argument, unlike the other two I have canvassed, would make physical proximity both necessary and sufficient for the duty of rescue to obtain. But if it proves to be less than compelling as a stand-alone argument - perhaps because of the difficulty in establishing the outer bounds of the sphere over which a person can claim sovereignty - then it can be taken together with unique vulnerability and personal encounter as features explaining the role that proximity plays in explaining the shape of the duty of rescue. In standard cases, all three features are present. As I noted above, this would also make room for exceptional cases in which vulnerability and/or encounter at a distance would be sufficient to trigger a duty of rescue.

A critic might still insist that the reference to proximity is unnecessary. Why isn't it enough, in order for the duty to arise, that the victim is threatened by severe harm which the rescuer can prevent at modest cost to himself, regardless of whether he is close to the victim or far away? One answer is that although in those circumstances the rescuer will always have a reason to help the victim, to turn this into an obligation would potentially diminish her freedom severely. Admittedly, in the world as it is, the responsibility to protect others' basic rights is usually a shared responsibility, not one that falls on particular individuals. But in principle it could so fall, and in such a way that it became very demanding. By limiting the normal obligation to rescue to cases where the victim is close to the rescuer, we also limit its demandingness, since there will be very few circumstances in which I find myself

\footnotetext{
${ }^{28}$ How far it is permissible to go in avoiding rescue situations remains an open question. We may owe it to our fellow human beings not to disable ourselves in such a way that we could never carry out a rescue; more positively, we may have a responsibility to equip ourselves with basic skills like first aid (for an extended argument in this direction, see Chiara Cordelli, 'Prospective Duties and the Demands of Beneficence,' Ethics 128 (2017-18), pp. 373-401). Nonetheless, deliberately avoiding danger spots for that reason seems to me a character flaw rather than the breach of a duty.
} 
physically close to someone in need of rescue. ${ }^{29}$ This should help to mollify libertarians and Kantians who oppose (uncontracted) positive duties of justice because of their implications for individual freedom. ${ }^{30}$ Imposing a duty of rescue does constrain freedom, but only marginally and in a way that ensures that the constraint is widely distributed among potential duty-bearers. Anyone might on rare occasions need rescue, and anyone might be called upon to provide one by virtue of proximity. ${ }^{31}$

IV

I now want to consider how the duty of rescue should be understood when there are multiple potential rescuers close to the victim. Does each member of the group have a duty of justice to carry out the rescue? This is a question that cannot be avoided by those who want to apply our intuitions about rescue to wider issues such as global poverty, where there are millions of potential duty-bearers.

When multiple rescuers are present, there are three main cases to distinguish. The first occurs when the rescue cannot be carried out unless the rescuers co-operate: they need to divide the task between them. In the second case only a single rescuer is needed, and the issue facing the group is who that person should be; one person, let's say, must swim out and pull the drowning bather back to shore. Then third, there will be cases in which the rescue could be performed single-handed at relatively high, but still not excessive, cost, while if the rescuers work together, the cost can be shared equitably between them.

The position I want to defend is that in all of these cases the duty of rescue is initially held collectively by the whole group. ${ }^{32}$ They must then co-ordinate their actions in such a way as 29

The significance of the fact that the duty of rescue is only triggered very occasionally and in relation to specific individuals is underlined in David Schmidtz, "Islands in a Sea of Obligation: Limits of the Duty to Rescue,' Law and Philosophy 19 (2000), pp. 683-705, and in Woollard, Doing and Allowing Harm, chs. 7-8. 30

Strict libertarians will of course continue to object to the duty on this ground; they will say that even if rescues are very rare, there can still be no obligation to undertake them. 31

Where this is not so - where there is a high chance that people will need rescuing - the duty should be (and often is) assigned to paid professional rescuers - lifeguards, helicopter crews, and so forth. 32

Stephanie Collins has argued that until the bystanders form themselves into a collective with a decision procedure, they cannot bear such a duty: see Stephanie Collins, 'Collectives' Duties and Collectivization Duties,' Australasian Journal of Philosophy 91 (2013), pp. 231-48. Yet she 
to give one, some, or all members a specific duty to perform. This co-ordination might be express - for example the group draws straws to decide who is to jump into the water - or it might be tacit, as when Anne takes one oar, Bill takes the other, and Cecile pushes the boat into the water without words being spoken. So here we find a collective duty of justice held by the group, which initially takes the form of a duty to co-ordinate their actions, giving rise to individual duties of justice on the part of the members to carry out whatever task has been assigned to them. This is subject to the rider that the distribution of individual duties must be fair: the costs of carrying out the rescue need not be exactly the same for all, since some may have capacities that others lack, but if Darren is nominated as the lone rescuer because of prejudice among the other members against people of Darren's type, he is not required as a matter of justice to perform the rescue. I return later to cases in which people who lack a duty of justice may still have a duty of a different kind to carry out a rescue.

But what if there is a failure to co-ordinate? Consider the position of Alice, who tried to get the bystanders to agree on a course of action, and signaled that if she were chosen as sole rescuer, she would comply, but whose efforts failed through the indifference or bloodymindedness of the others. Is Alice now required as a matter of justice to rescue the bather? She sees nothing that would pick her out as the relevant savior; in fact she thinks it very likely that there are others in the group who could effect the rescue more easily. If indeed she has an individual duty of rescue, it must be one that she had all along, something that was merely disguised by the presence of other potential rescuers. According to this view, each person present on the beach who could carry out the rescue at reasonable cost had a duty of justice to rescue the bather; it is just fortuitous from their point of view if somebody pre-empts them by jumping into the water, or being chosen to do so, thereby releasing them from their duty.

I believe that this picture misrepresents Alice's moral situation. In the circumstances described, where co-ordination fails, she has at least a strong moral reason, but not a duty of justice, to rescue the bather. ${ }^{33}$ That duty itself remains with the collective until it is transformed into a set of individual duties by one of the mechanisms outlined above. Think, acknowledges that they have a duty to collectivize, and it is hard to make sense of that except as a way of implementing a prior duty of rescue. 33

I consider below whether Alice may have a duty of a different kind - a humanitarian duty - to rescue the bather. 
by analogy, of the case where Ben and Charles, two unrelated individuals, borrow Mary's car for the day, promising to return it in pristine condition. Unfortunately the car is accidentally damaged in the course of the outing. Unless they agree something else between them, each should pay half the cost of the repair. If Ben refuses to pay, Charles is not under an obligation to cover Ben's share. He may have reason to pay - he may think that Mary shouldn't have to suffer for her generous gesture - but he isn't required to if Ben is simply unwilling to fulfill his obligation. ${ }^{34}$

This analysis can be applied to a case that has generated some discussion in the philosophical literature, namely one in which there are multiple potential rescuers and multiple victims in need of rescue. ${ }^{35}$ Imagine that there are five of each, and assume that under a fair assignment of responsibility each rescuer has a duty to rescue one, and only one, victim. But suppose now that four of the five potential rescuers turn away. Does the remaining rescuer then acquire a duty of justice to salvage all five victims? On my view, clearly not. The mere failure of the four rescuers to discharge their duties cannot transfer those duties to rescuer number five, any more than Ben's failure to pay for the damaged car creates an additional duty of justice for Charles. ${ }^{36}$

34

Note, however, that there can be groups of which it is understood to be a condition of membership that each person should be ready to stand cover for the others if they default on a debt. With a group of that kind, someone who has a claim of justice against the group can also lodge it against any of the individual members. It should be clear enough, however, that a number of people randomly present at the water's edge don't constitute such a group.

${ }^{35}$ See, for example L. J. Cohen, 'Who is Starving Whom?,' Theoria 47 (1981), pp. 65-81; Liam Murphy, Moral Demands in Nonideal Theory (New York: Oxford University Press, 2000), ch. 7; David Miller, 'Taking Up the Slack: Responsibility and Justice in Situations of Partial Compliance' in C. Knight and Z. Stemplowska (eds.), Responsibility and Distributive Justice (Oxford: Oxford University Press, 2011), pp. 230-45, reprinted in D. Miller, Justice for Earthlings (Cambridge: Cambridge University Press, 2013), pp. 206-27; Anya Karnein, 'Putting Fairness in its Place: Why there is a Duty to Take up the Slack,' Journal of Philosophy 111 (2014), pp. 593-607; Zofia Stemplowska, 'Doing More than One's Fair Share,' Critical Review of International Social and Political Philosophy 19 (2016), pp. 591-608. 36

To be clear, my claim is that the original duty of justice does not transfer when one or more parties default. This is consistent with recognizing that the default may have the effect of creating new duties of a different kind. For example, suppose that Mary is heavily reliant on the use of her car perhaps she is partially disabled. Then Charles might have a duty to pay for the other half of the damage - but this would not be a reparative duty of justice, but a duty of friendship or charity not connected with his use of the car. In a similar way, when the four potential rescuers default, the fifth person may acquire a humanitarian duty to try to save the victims they should have rescued. 
But, critics will argue, the rescue case is unlike the car case because the basic rights of the victims are at stake in the former but not the latter. If the compliant rescuer turns his back on the four victims, then those four will perish - whereas the rescuer could have saved them at additional, but still reasonable, cost, let us assume. Surely there must be a duty of justice to carry out those further rescues, even though it's clearly unfair for one person to have to incur all of that cost? The single rescuer will certainly have a complaint against the four who defaulted, but that doesn't relieve him of the duty he owes to the potential victims. ${ }^{37}$

Although basic rights are clearly at stake in rescue cases, it isn't the mere fact of being able to protect those rights that creates a duty of rescue. There must be something specific to the relationship between rescuer and victim that hooks them together in such a way that rights on one side generate an obligation on the other. ${ }^{38}$ In my analysis of the single rescuer case, I argued that it was the physical proximity of the two parties, together with the immediate threat of harm to the victim, that gave the rescuer a duty to protect him. I gave reasons why proximity has this normative significance. But in the multiple rescuers case, where each potential rescuer is close to the victim, that space is already occupied by other agents, all potentially capable of contributing to the rescue. So how can each be obliged, as a matter of justice, to rescue all five victims? What special feature does any individual rescuer possess that hooks her to all the victims in such a way as to create that obligation?

37

The point is sometimes put as follows: maintaining fairness between duty bearers may be important, but why should this trump the duty owed to the victims? Michael Ridge, for example, has characterized the non-compliance problem as a matter of fairly distributing the burdens of noncompliance between the remaining rescuers and the victims: see Michael Ridge, 'Fairness and NonCompliance' in B. Feltham and J. Cottingham (eds.), Partiality and Impartiality (Oxford: Oxford University Press, 2010), pp. 194-222. But on the view that I am defending, fairness plays a different role: it serves to determine the extent of each individual rescuer's duty of justice, identifying what portion of the collective's responsibility she bears. Fairness here is not a goal to be achieved, but a criterion for assigning duties.

${ }^{38}$ Those who defend the strict correlativity of rights and obligations will argue that until the holder of the corresponding obligation is identified, there is no right to be rescued. Whatever the merits of strict correlativity for purposes of legal analysis, in the cases under discussion it makes sense to identify obligation-generating rights while leaving it open, at the first stage, what form the corresponding obligations will take and where they will fall. This allows in particular for the sequencing of obligations. Thus, as indicated above, in a rescue case, a bystander's first obligation may simply be to co-ordinate with others on the scene; and then at some later point may have a second obligation to carry out a specific part of the rescue (or no such obligation if his contribution would be redundant). 
The critics I have in mind may still be unconvinced. Given that the other bystanders are as a matter of fact unwilling to carry out their share of the rescue, why is their presence on the beach or the river bank relevant to determining the content of my duty? Isn't it just as if they were never there at all? In that case I would have had an obligation to rescue all five victims, which, we are assuming, I could have done at greater but still reasonable cost. How can the presence of four other practically inert people reduce that obligation?

It is important to underline that in the scenario being envisaged, the four bystanders are inert only because they choose to be. They are not unaware of the emergency, physically incapable of carrying out the rescue, or paralyzed by fear. They are simply refusing to act on what is plainly their duty of justice. It would surely be odd to maintain that what a person is morally obliged to do is unaffected by the presence of other agents who are subject to the same moral requirements as she is. To say this would be to abandon the idea that morality, or more specifically justice, is to be understood as providing directives that apply to all moral agents in the same way, insofar as they are similarly situated. Its principles tell us how to act on the assumption that others, too, will follow them. There may be other moral reasons that apply in circumstances where that assumption fails - supplementary directives that address that situation. But we misunderstand justice if we think that its purpose is to tell us how to act even when all around us are ignoring its injunctions.

Return now to the case in hand, where I and the four inert bystanders have five victims to save. After I have rescued the first, and it has become clear that none of the others is willing to act, I will then have a very strong reason to try to save the remaining victims, provided that the cost is not excessive. Indeed I may have a duty, though not a duty of justice, to do so. ${ }^{39}$ This duty will not be enforceable, nor can the victims claim to have been wronged by me if I fail to discharge it. The wrong has been perpetrated by the four people who were unwilling to do anything at all.

39

We can speak of a duty here if we accept that there can be duties without corresponding rights. An example would be duties of gratitude, whose performance the beneficiary has no right to demand. The language of duty is here being used to signal that the duty bearer would be at moral fault if she fails to do what she is obliged to do, even though no one can make her do it; her action is not merely supererogatory. In the rescue case, the person who takes up the slack that others have left will often have a humanitarian duty to do so. 
If one starts by making the assumption that each of the rescuers has a duty of justice to rescue all five victims if necessary, such distinctions will necessarily be obliterated. If I owe the same duty of justice to victims 2-5 as I owe to victim 1 , then my moral relationship with victims 2-5 is unaffected by the fact that I have carried out my (fairly assigned) duty to victim 1. If they wish to claim compensation for the injuries they have suffered as a result of not being rescued, they have as much reason to sue me as they have to sue the other four. But this is surely repugnant: saving them was the others' job, not mine. To avoid that conclusion, we need to distinguish between the primary duty of justice, and the secondary duty I may have to take up the slack if others fail in theirs.

This conclusion might be resisted because of ambiguity over how the initial duty of justice should be allocated. So consider a case in which there is no ambiguity. Suppose that I am on a beach and notice someone out to sea thrashing about in a way that alarms me. There is a lifeguard on the beach, posted there for just this purpose. I alert the lifeguard, who is nonchalantly eating his lunch. The lifeguard replies that once he has finished his beer and his sandwich, he will give the matter his attention. Since it's clear that the situation is urgent and that the lifeguard is not going to move for some time, I jump into the water and save the bather. I act on a humanitarian duty, directly triggered by the lifeguard's failure, as the designated rescuer, to do what justice requires him to do. To collapse the distinction between the two kinds of duty would be to block out morally relevant features of the situation. If I have the power, I can force the lifeguard to save the bather; he has no corresponding right to force me..$^{40}$ If I incur costs in the course of the rescue, I can demand compensation from the lifeguard; again there is no equivalent right on the lifeguard's side.

If this analysis of the lifeguard case is accepted, how is the multiple rescuers case different? The lifeguard's duty has been formally assigned, whereas in the multiple rescuers case, it relies on the idea of a fair division of responsibility - there are five rescuers and five victims, so each should rescue one of them. ${ }^{41}$ This is where ambiguity might creep in: perhaps one 40

What if a non-swimmer on the same beach with the power to coerce witnesses my verbal exchange with the lifeguard? His first move must surely be to force the lifeguard to stop eating and carry out the rescue. But suppose that he cannot get the lifeguard to move quickly. May he then force me to swim to the rescue? About this I am uncertain. In general, humanitarian duties are unenforceable. But there might be exceptions to this in cases where the cost of carrying out the duty is minimal and the benefit very great. 41 
of the rescuers is actually going to find it very difficult to do what is being asked of him (he has a strong fear of drowning, for example), while another is a strong swimmer for whom the prospect of two rescues in a short space of time poses no problems. So here fairness may require a different division of responsibility. The basic point remains that once the fair division becomes clear, so that each knows what he or she is required to do, that is what can be demanded of them as a matter of justice.

Admittedly, the normative analysis I have presented depends upon viewing the multiple rescuers case in a particular light. The members of the relevant group are understood not only as being physically capable of contributing to the collective rescue, but as moral agents responsive to the reasons for carrying it out. Like most human beings, they may be tempted to hold back in the hope that someone else will pre-empt them by jumping into the water, but they recognize that they are subject to a duty of rescue, and they understand the idea of a fair division of responsibility. None of this will apply in the case of an assembled group who are actively hostile to the victims and wish them harm. In that case the wellintentioned rescuer has to adopt a straightforwardly strategic attitude towards the other people present, regarding them either as obstacles to be circumvented or (possibly) as tools to be made use of in the course of the rescue. But if we are interested in the normative question of how the duty of rescue should be understood in circumstances where there are multiple potential duty-bearers, then of course we need to assume that these duty-bearers might indeed do what they have reason to do. And this is certainly the assumption made by those who appeal to the duty of rescue to throw light on larger issues such as global poverty.

V

So, to conclude, what this investigation shows is that the duty of rescue is a stringent duty, but one that has quite a narrow scope. It cannot be subsumed under a general consequentialist duty to avoid harm, nor can it be understood as part of a reciprocal duty of citizenship. It is a rare example of a positive duty of justice that applies to individuals regardless of any prior social connection between the bearer of the duty and its object.

An intermediate case is one in which the five rescuers, having appraised the situation, make a commitment to each other to share the rescue, perhaps identifying which victim each is to save. Here the duty of justice that each bears is formally defined. 
Exceptional cases aside, it depends upon the rescuer being uniquely close to the victim. But when multiple rescuers are present, the collective duty that falls on the group has to be distributed among its individual members before we can say what each is required to do as a matter of justice.

Because the duty has this shape, it cannot be stretched to apply to wider issues of moral and political philosophy in the relatively straightforward way that authors such as Singer imagine. ${ }^{42}$ Of course when we address issues such as global poverty, or refugees, or the supply of vital body parts, we are also dealing with instances in which human rights are at risk. But whereas in the case of the duty of rescue, we begin from the simplest case - one rescuer, one victim - and then examine what happens to the duty when we complicate the story (victims responsible for their own plight, multiple rescuers etc.), in these other cases the primary issue will always be who bears the responsibility that might crystallize into an obligation to protect these rights. ${ }^{43}$ The duty to rescue is special because that question is solved in the simplest way imaginable, by an immediate encounter between two human beings, one utterly dependent on the other at that precise moment in time.

\section{Acknowledgements}

Earlier drafts of this paper were presented to the Queen's University Philosophy Colloquium, to a workshop organized by the Philosophy Faculty, Cambridge University, to the Nuffield Political Theory Workshop, to the University of Sydney Philosophy Seminar, and to the Australian National University Philosophy Seminar. I should like to thank members of each of these groups for their penetrating comments. Special thanks to Paul Billingham, Linda Eggert, Cécile Fabre, Margaret Moore, Fergus Peace and Andrea Sangiovanni, and an anonymous reviewer for their written suggestions.

\footnotetext{
${ }^{42}$ This is demonstrated in the case of humanitarian intervention by Bernard Williams in B. Williams 'Humanitarianism and the Right to Intervene' in Bernard Williams, In the Beginning was the Deed, ed. G. Hawthorn (Princeton: Princeton University Press, 2005), pp. 145-53.

43 I have tried to tackle some of these questions elsewhere: see David Miller, 'Distributing Responsibilities,' Journal of Political Philosophy, 9 (2001), 453-71; David Miller, National Responsibility and Global Justice (Oxford: Oxford University Press, 2007), esp. ch. 9; David Miller, 'The Responsibility to Protect Human Rights' in L. Meyer (ed.) Legitimacy, Justice and Public International Law (Cambridge: Cambridge University Press, 2009); David Miller, 'Our Responsibilities to Refugees' in M. Hoesch and L. Laube (eds.), Proceedings of the 2018 ZiF Workshop "Studying Migration Policies at the Interface between Empirical Research and Normative Analysis", ULB Münster (miami.uni-muenster.de), doi: 10.17879/95189441435.
} 


\section{Biographical Note}

David Miller is Professor of Political Theory at the University of Oxford and Visiting Professor of Law and Philosophy at Queen's University, Ontario. Among his books are National Responsibility and Global Justice (2007) and Strangers in Our Midst: the Political Philosophy of Immigration (2016). 